\title{
Syntactic Functions of Infinitives in English
}

\author{
Sara Quintero Ramírez \\ University of Guadalajara \\ Calle Guanajuato 1045, Alcalde Barranquitas, 44260 Guadalajara, Jalisco, México \\ E-mail address: qsara@hotmail.com
}

Received: 12-07-2014

Accepted: 06-09-2014

Published: 01-01-2015

doi:10.7575/aiac.ijalel.v.4n.1p.182

URL: http://dx.doi.org/10.7575/aiac.ijalel.v.4n.1p.182

\begin{abstract}
The purpose of this paper is to present an overview of the most relevant syntactic functions of infinitives within the sentence in English, based on the British 2006 Corpus (BE06) designed by Paul Baker and displayed by the server of Andrew Hardie, Corpus Query Processor (CQPweb). The corpus reveals that infinitives are a very frequent non-finite form employed in English. The most relevant syntactic functions that infinitives took in the corpus were as verbal periphrasis, as verb complements, as noun complements, as adjectival complements, as nominal predicates and as verb subjects. In English there are specific contexts in which the infinitive is not preceded by the particle to, such as after an extensive number of auxiliary, perception and permission verbs. Furthermore, there are other specific contexts in which the infinitive is preceded by the particle to, such as after a large number of direct objects in transitive verbs and functioning as a verb subject and as a noun or adjective complement. The major claim of this study is that infinitives in English do not constitute a uniform group; in fact, they display a variety of syntactic functions within the sentence directly reflecting their nominal and verbal properties.
\end{abstract}

Keywords: bare infinitive, full infinitive, infinitive phrase, syntactic function, BE06, CQPweb

\section{Introduction}

Infinitives are defined as non-finite forms that in many European languages (such as English, French and Spanish) have a bare form (En., speak, walk, work; Fr., parler, marcher, travailler; Sp., hablar, caminar, trabajar) and a form preceded by a specific particle (En., to; Fr., de; Sp., de) and they "[...] have both nominal and verbal features, both aspects of the content being (often) apparent in the same context" (Schybsbye, 1965: 61). In English, French, Spanish and other languages, this non-finite form occurs in many constructions in an assortment of text genres. The objective of this paper is to identify the main syntactic functions that infinitives in English fulfil within the sentence.

In order to arrive at the objective of this study, the paper is organized as follows. First of all, a preliminary section about the non-finite forms is presented; here non-finite forms are defined and characterized. Secondly, there is a section about infinitives in which we explain what an infinitive in some European languages is, its verbal and nominal characteristics and the most relevant syntactic functions infinitives display within the sentence. Then, in the methodology section, we explain how the corpus is constituted and how we proceeded in order to analyze it. Afterwards, we focus on the analysis of the corpus. Finally, the conclusions section summarizes the major claims of this study.

\section{Literature Review}

\subsection{General characteristics of non-finite forms}

In order to identify what an infinitive is, it is important to define the non-finite forms. To do this, it must be considered that the non-finite forms are seen as forms that have lost some verbal characteristics and simultaneously have acquired some nominal, adjectival or adverbial features. In other words, they are less finite, thus they are dependent verb forms. That is why in a variety of text genres, these non-finite forms can display very different syntactic functions from those displayed by the prototypical finite forms or verbs.

According to Raible (2001: 601), we have to consider the distance between the verb and the noun as a continuum which has the concepts of finiteness and non-finiteness as cornerstones, connected by the two gradients of increasing nonfiniteness/ decreasing finiteness and decreasing non-finiteness/ increasing finiteness (Note 1). Along the continuum we can situate a considerable number of intermediate instances in which gerunds, participles and infinitives are included. While a verb form loses its verbal (or finiteness) traits, it becomes more nominal, this means less finite or in other terms, more 'non-finite'. "According to this view, the intermediate categories such as the various types of participles in ENGLISH and other European languages not only differ in their increase in nominality [...], but also gradually lose their verbal characteristics as one moves along toward the right hand end of the continuum [...]" (Sasse, 2001: 500).

Sasse (2001: 495) asserts that non-finite forms are defined as hybrid categories that combine verbal and nominal characteristics. That is why they cannot be situated in a simple lexical category. Moreover, Ylikoski (2003: 190) states that non-finite forms usually fulfil syntactic functions that are considered atypical of finite verbs. Thus, it is reasonable that these forms take on a diversity of functions that do not belong to verbal categories per se. 
According to the classification offered by classical grammars, some researchers such as Rémi-Giraud (1988), Raible (2001), Ylikoski (2003) and others distinguish three main non-finite forms: a) participle, a non-finite form employed mainly in an attributive function, b) gerund, employed essentially in an adverbial function and c) infinitive, used especially in an object function. Iturrioz (2000: 99) states that even if these three categories are present in most of European languages, there is a prominent variation between them in the morphosyntactic level and in the functional one in each language.

\subsection{General characteristics of infinitives}

Rémi-Giraud (1988: 28) defines the infinitive as a verb form that conserves only the categories of aspect and diathesis, but loses the categories of mood, tense and person, although these are categories that infinitives can acquire from a contextual way. Gawelko (2005) adds that infinitives can be defined according to their syntactic frame, i.e., the possibility of combining with an auxiliary verb in order to form compound tenses and the possibility of governing arguments and adjuncts.

Besides these verbal characteristics, there are some languages, like Spanish and Italian, in which infinitives can be preceded by nominal determiners (articles, possessives, demonstratives, adjectives, etc.). So the infinitive preceded by nominal determiners or/and followed by verb complements constitutes an infinitive phrase. This infinitive phrase can take on a variety of syntactic roles such as verb subjects, nominal predicates, direct objects, verbal periphrasis, and a diversity of adverbial complements and independent constructions.

\subsection{Verbal characteristics of infinitives}

As it has been stated before, if we consider the distance between the verb and the noun as a continuum which has the concepts of finiteness and non-finiteness or verbiness and nouniness (Sasse, 2001) as cornerstones, we can situate a considerable number of intermediate instances and the infinitive is one of them (Raible, 2001). Thus, it is important to establish the relationship between the infinitive and the morphological verbal characteristics such as diathesis, tense, aspect, mood, person and number.

\subsubsection{Diathesis in the infinitive}

Diathesis is one of the main characteristics of the verb and it is also one category that the infinitive presents. RémiGiraud (1988: 68) asserts that most languages that have infinitives distinguish between the active and the passive infinitive. Tesnière (1976: 730) adds that Modern Greek, Latin, French, English, German, Hebrew and Turkish are just a few languages that have active and passive infinitives.

Example (1) is an instance of reflexive infinitive in French ("to look at oneself in a mirror"). Moreover, (2) is an example of reciprocal infinitive in Turkish ("in order to understand each other it is necessary to love one another"). There are also some languages like Hebrew and Turkish that have causative diathesis. Example (3) in Hebrew could be interpreted like "to make kill" according to Tesnière.

(1) Se regarder dans un miroir

(2) Anla, mak için sevişmek lâzimdir.

(3) Haqtêl (Examples from Tesnière, 1976)

2.3.2 Tense and aspect in infinitive

Tesnière (1976: 738) states that even if it lacks tense, the infinitive preserves the aspect from its verbal origins. The author offers some examples in Latin and Russian. Tesnière asserts that both languages possess an imperfective infinitive (Lat. capere - "take", Rus. pisat" - "write"), and one perfective infinitive (Lat. cepisse - "have taken", Rus. napisat'- "have written").

Rémi-Giraud (1988: 17) observes that the infinitive can display certain characteristics that even if they are not specifically temporal, they are related with time, especially with sequence, expressing the order in which a process happens, and indicating if this process happens before, after or at the same time as other processes. Through the perfective infinitive, for example in French (avoir fait - "have done"), we know that we are expressing an action that has happened before another one that is expressed through an imperfective infinitive (faire - "do"). Besides, most of the times, the temporality of the infinitive is interpreted by the cotext and the context in which it is used.

\subsubsection{Mood in the infinitive}

Tesnière (1976: 732) asserts that mood is a category that reflects a psychological attitude of the interlocutor in relation to the process that is expressed by the verb. In other words, it is a technique of modality in which attitudes can be very diverse and nuanced, and grammarians have not been able to agree to present a consistent theory. However, the infinitive can assume some modal nuances.

Tesnière adds that modalities that infinitives display do not really belong to the infinitive per se, but the infinitive acquires those modalities because of the cotext and the context in which it is used. An example of this can be the imperative infinitive (in Spanish, French, Italian and other languages) that is used as a verb form in imperative modality in order to give advice, recommendations, orders, etc. Example (4) is an instance of imperative infinitive in Italian ("turn off the engine during stops"). 


\subsubsection{Person and number in the infinitive}

If we consider a morphologic perspective, the infinitive lacks the category of person in most languages, except for those languages that have a personal infinitive such as Portuguese, Sardinian and Galician. Nevertheless, in the sentence we can see that the infinitive has other mechanisms in order to express this category. For example, in some Romance languages such as French, Italian and Spanish, if the subject of an infinitive is not expressed, it is because it keeps the subject of the main verb. We can see this in example (5) in which the second person singular (tu - "you") is the subject not only of the main verb (volere - "want") but also of the infinitive (venire - "to come"). Thus, when the subject of an infinitive clause is different to the subject of the main verb, it is obligatory to express it, as it is done in example (6) where the subject of the main verb (prier - "solicit") is the first person singular (je - "I"), but the subject of the infinitive (croire - "to believe") is the second person singular (vous - "you"). It is important to notice that the infinitive is introduced by the element $d e$.

Vuoi venire a scuola con me?

(6) Je vous prie de croire, Monsieur, en l'expression de ma parfaite considération (Examples from blogs from the Internet)

\subsection{Nominal characteristics of infinitives}

We have already discussed the verbal characteristics of the infinitive in different European languages. It is also important to talk about its nominal characteristics. Gawelko (2005: 135) presents some nominal characteristics that differentiate the infinitive of Romance languages from the infinitive of other European languages.

According to the results that Gawelko obtained in his typological study, Portuguese, Italian and Spanish infinitives have more nominal characteristics than the infinitives from other languages, i.e., French or English. In (7) and (8) we can appreciate two examples of infinitives preceded by nominal determiners and one of them followed by verb complements. In the example in Spanish, the verb tutearse ("to address informally") is preceded by the demonstrative determiner ese ("that"), and it is also followed by an adjective and a prepositional phrase (de ellos dos/ "of the two of them"). In the other example we notice the Italian infinitive pensare ("to think") that is preceded by the determiners $i l$ and mio ("the" and "my") and it is followed by an indirect object (a tel "about you").

(7) Ese tutearse continuo de ellos dos... (Example from Hernanz Carbó, 1982: 511)

(8) Vorrei che il mio pensare a te non fosse più un continuo tormento ma un lido raggiunto. (Example from a blog from the Internet)

Buridant (1990: 154) adds that in contemporary French, nominalization with infinitives is not very common. One example is (9) in which infinitives boire and manger ("to drink" and "to eat") are preceded by the demonstrative determiner ce ("this"), but both infinitives are followed by verb complements, direct object le Sang de Christ and sa Viande ("the Blood of Christ" and "his Flesh") respectively.

(9) Ce boire le Sang de Christ et ce manger sa Viande, c'est la Vérité, c'est l'Amour. (Example from Quintero Ramírez 2012: 161)

In German, Rémi-Giraud (1988: 55) claims that one particularity of this language is that nominalization of infinitive is even higher than in Romance languages because any nominalized infinitive like Essen ("eat") in (10) can be considered a noun like Wein ("wine"). As we can appreciate, Wein and Essen are preceded by evaluative determiners, guten and gutes ("good") respectively, and both phrases are considered verb complements, more particularly direct objects.

Du liebst guten Wein und gutes Essen ? (Example from a blog from the Internet)

\subsection{Double nature of infinitive phrases}

In the examples we have presented above, Spanish, Italian, French and German infinitives are preceded by typical noun determiners such as demonstratives, possessives and even evaluative adjectives, but infinitives are also followed by arguments and adjuncts (Note 2). Thus, infinitives are considered to be in the nominal category and in the verbal category. Infinitive phrases in different languages can display different nominal roles, such as verb subjects, verb complements, nominal complements, etc. That is why the infinitive is considered an intermediate category on the continuum we have designed at the very beginning of this paper, although nominal and verbal characteristics vary from one language to another (Rémi-Giraud, 1988; Haspelmath, 1989; Mayerthaler et al., 2001; Raible, 2001; etc.).

Hence, as we have seen, the infinitive can display nominal and verbal characteristics. In fact, these two characteristics do not represent a dichotomy but they are complementary. There are infinitives that can be preceded by nominal determiners without losing the possibility of taking verb complements.

\section{Methodology}

\subsection{Corpus}

In this research, we intend to present the most relevant syntactic functions that English infinitives can display based on the BE06 Corpus designed by Paul Baker. Actually, the BE06 Corpus is a one-million word reference corpus of British English that consists of 500 files of 2000 word samples of four main genres: press, general prose, learned writing and fiction. These four genres are further subdivided into 15 writing sub-genres. All the texts were published between 2003 and 2007 and they can be found on the Internet. It has been called British English 2006 (BE06) because the median sampling point is 2006 (Baker, 2009). 
We decided to work with the BE06 Corpus because we consider it to be an updated corpus that has an adequate amount of texts in order to locate an assortment of syntactic functions displayed by the infinitive phrases in one of the most expanded varieties of English language, i.e., British English.

In order to determine the most relevant syntactic functions of the English infinitive in the corpus, we have used the CQPweb provided by the server of Andrew Hardie.

CQPweb is a new web-based corpus analysis system, intended to address the conflicting requirements for usability and power in corpus analysis software. To do this, its user interface emulates the BNCweb system. Like BNCweb, CQPweb is built on two separate query technologies: the IMS Open Corpus Workbench (Note 3) and the MySQL relational database. CQPweb's main innovative feature is its flexibility; its more generalised data model makes it compatible with any corpus. The analysis options available in CQPweb include: concordancing; collocations; distribution tables and charts; frequency lists; and keywords or key tags. (Hardie, 2012: 380)

In order to carry out our search of syntactic functions of the infinitive, we have performed a simple query language syntax using the annotations of UCREL (University Centre for Computer Corpus Research on Language), CLAWS (Constituent Likelihood Automatic Word-tagging System) (Note 4), 7 Tagset which is the way the BE06 Corpus has been grammatically annotated at CQPweb. The analysis options that we have used were basically concordancing and collocation.

\subsection{Categorization of the corpus}

For the analysis of the corpus, we have considered the syntactic functions of the infinitive phrase that have been presented in the literature review. We have mainly considered proposals of Rémi-Giraud (1988), Haspelmath (1989), Turner (2000) and Mayerthaler et al. (2001). Based on their studies, we have designed the following categorization:

1. Infinitive phrase as a complement of a verb or a predicate

2. Infinitive preceded by an auxiliary verb: verbal periphrasis

3. Infinitive phrase as a verb subject

4. Infinitive phrase as a nominal predicate

5. Infinitive phrase as a complement of an adjective

6. Infinitive phrase as a complement of a noun

It is important to state that in this paper we are not going to analyze other syntactic functions displayed by the infinitive in English such as the infinitive phrase in adverbial clauses or the infinitives that are used in independent constructions, because we will consider them in further studies as functions of the infinitives in English from a suprasentential perspective.

\section{Results and Discussion}

Rémi-Giraud (1988) considers that according to their function in the sentence, infinitive phrases can be verb subjects, noun complements, adjective complements, verb complements (arguments and adjuncts), verbal periphrasis and independent constructions. Most of the researchers that study infinitives state that their main syntactic function is as complements (Rémi-Giraud, 1988; Haspelmath, 1989; Mayerthaler et al., 2001; Ylikoski, 2003). Moreover, Ylikoski (2003: 207) states that without going too deeply into this matter, infinitives can be used: a) as complements of manipulative verbs, desiderative verbs and modal verbs; $b$ ) as complements of adjectives and nouns; and c) as adverbial clauses (obligatory and optional).

Hapelmath (1989: 298-299) adds that infinitives can be used in different kinds of complement clauses such as directive verbs (order, ask, cause), desiderative verbs (desire, want, prefer), modal predicates (be possible, be able, be necessary), evaluative predicates (be interesting, be funny, regret), thinking verbs (think, believe), verbs of utterance (say, claim, report), and cognition verbs (know, realize, find out).

Mayerthaler et al. (2001: 65) develop Haspelmath's perspective and with a list of sentences in nine languages (Portuguese, Spanish, French, Italian, English, German, Russian, Finnish and Greek), they study the role of the infinitive phrase as verb complement in those languages. Their study is considered a representative transversal crosssection of the present-day linguistic standard material.

Mayerthaler et al. (2001) design the study based on a scheme in which they present the infinitive as a predicate with auxiliary verbs, movement verbs, intentional verbs, permission verbs, perception verbs, aspectual verbs, directivity verbs, expectative verbs, manipulative verbs, communicative verbs, cognitive verbs, etc. Finally, they consider the infinitive in adverbial clauses such as final clauses, cause clauses and modal clauses. The authors examine if the infinitive construction exists in those contexts, and if it does, then if the infinitive is possible or obligatory; this means that they consider if there is the possibility in each language to express the same thing with finite constructions or if the infinitive represents the only option.

For practical purposes of our analysis, it is important to establish that the infinitive form without to will be called bare infinitive; while the form introduced by the particle to will be called full infinitive. The bare infinitive and the full infinitive have an assortment of uses that are regularly found in complementary distribution. As it will be seen in our analysis, certain syntactic contexts ask for the bare infinitive while other specific syntactic contexts require the full 
infinitive. They are only interchangeable in very specific circumstances, such as after the verbs help, need and dare, as it will be examined later.

\subsection{Infinitive phrases as verb complements}

Based on the Mayerthaler et al. (2001) model, we will consider the different verbs and predicates after which English infinitive is used in the BE06 Corpus. In this language, the degree of prominence, according to Mayerthaler et al. (2001: 76), is less than in Romance languages such as Portuguese, Spanish, French and Italian. The most important fact in English is that the infinitive competes with the gerund form - ing in many syntactic functions. It is important to state that gerunds are found more frequently in most of the contexts presented by Mayerthaler et al. This morphosyntactic peculiarity means that infinitive constructions in most of the contexts are only possible but not obligatory, an important difference between English and the four Romance languages we have mentioned.

On the one hand, the -ing form in (11) refers to an action that can take place in the future, i.e., a potential action. With the use of the infinitive a completed/ concluded action is described, as in (12). Mayerthaler et al. (2001) and Gawelko (2005) tell us that gerund clauses in English are more commonly used than infinitive clauses. Besides, Mayerthaler et al. assert that the gerund is used more in a general way, while the infinitive is only used in contexts that present a more specific situation, especially the explicit subject. Nevertheless, in the BE06 Corpus we could not corroborate Mayerthaler et al.'s claim. The only aspect we could find out in our corpus was that with modal and evaluative predicates, the full infinitive is more common than the -ing form. In fact, in our search for modal and evaluative predicates + full infinitive, the CQPweb displayed 529 examples; whereas, in our search for modal and evaluative predicates + -ing form, the system showed only163 examples.

(11) I am a 34-year-old fun-loving woman interested in meeting someone similar.

(12) On this occasion I was as interested to know how they got on in the recent local football derby against Longridge as they were to know what had gone wrong in England's Six Nations defeat against Ireland.

On the other hand, infinitive constructions with perception verbs deserve our attention, since in English the -ing form is more used according to Mayerthaler et al. (2001), because the infinitive clause establishes a restrictive meaning. This is exactly what we have found in the corpus. Moreover, with perception verbs bare infinitives are used, as we can appreciate in (13) and (14); (15) and (16) represent two examples with perception verb + -ing form. Even if the difference is not so vast, in the BE06 Corpus we have found more examples with the -ing form than with the bare infinitive, as Mayerthaler et al. (2001) and Gawelko (2005) state in their respective research papers. More specifically, in our corpus we have observed 51 examples with the -ing form and 40 examples with the bare infinitive.

(13) I imagine Tweedle Dee and Tweedle Dum make it their business to see you get what you want. Georg and Karl. You give them names?

(14) My Dad has noticeable ears, a kindly expression and a suit for work. Sometimes people hear him speak and think he is Australian.

(15) They usually managed to grab a meal somewhere once every couple weeks, just the two of them, but most evenings this year had seen him disappearing downstairs after dinner, screwdriver in hand and a pleasurably preoccupied look on his face.

(16) She seemed to be a moody woman; during breakfast Muriel had heard her shouting at her husband.

With causal verbs such as make, and permission verbs such as let, the infinitive construction is not introduced by any particle as in (17) and (18). The search of these two verbal constructions in the BE06 Corpus showed 185 matches. However, with other permission verbs such as permit and allow, the infinitive phrase is preceded by the particle to, as can be observed in (19) and (20) respectively. In both cases we can see the permission verb permit/ allow + direct object + full infinitive. The search of these two verbal constructions in the corpus showed 67 matches, 61 of them with the verb allow and only 6 with the verb permit.

(17) She likes them and will make them work, despite her apparent lack of natural talent.

(18) Ultimately, they were only too happy to let someone else take responsibility.

(19) Improvements in model specification have permitted analysts to estimate the unique impact of variables.

(20) It is possible to allow students to vote with 'high' or 'low' confidence, which provides the lecturer some idea of a student's certainty of their answer being correct.

Turner (2000: 95) states that when make does not have a causal meaning, but an obligation meaning, the syntax changes and the infinitive phrase is introduced by the particle to, as in example (21) which he presents in his study. Nevertheless, in the BE06 Corpus we did not find any example with such characteristics. What we have observed in the corpus is that with other obligation verbs such as force or oblige, the infinitive phrase is preceded by the particle to, just as can be distinguished in examples (22) and (23). In the BE06 Corpus, we have carried out a query of the verbs force/ oblige + full infinitive and we have found 17 examples that matched these characteristics.

(21) For all averred I had killed the bird that made the breeze to blow (Example from Turner, 2000: 95)

(22) Perhaps, it occurs to me, locking up the old Citron, perhaps since it was built round the stadium, the whole purpose of this suburb was to design a place of such spiritual emptiness as to more or less oblige everybody to go to the game on Sundays. 
(23) Elliot was a diplomat and he only liked bitching about Isabelle on his own terms (usually when he was drunk) but not like this, not when Kellie tried to instigate conversations that would force him to say unkind things.

Turner (2000: 105) says that the verb help is usually followed by a nominal phrase that displays the role of direct object and then a bare infinitive or also a full infinitive. The author does not offer specific information about why users of the language prefer to use the full infinitive or the bare infinitive, and the examples we have found in the corpus do not give us a clue either. In their study, McEnery \& Xiao (2005) discovered that American English has a stronger preference for bare infinitives after the verb help than British English. In our corpus, we have found 44 examples with the bare infinitive and 13 examples with the full infinitive. In example (24) we notice the following structure: help + direct object + full infinitive and in (25) we observe help + direct object + bare infinitive.

(24) This was pleasing to the lecturers involved, as these results compared favourably with those from the previous year and showed that a change in the syllabus can help students to understand a "troublesome concept".

(25) Further steps in delivering our commitment to help communities tackle bad landlords and long term abandoned empty properties come into force tomorrow.

If we consider what Haspelmath (1989: 298-299) and Ylikoski (2003: 207) have stated earlier about the most common contexts where infinitive phrases can be used as complements of verbs and predicates, we have confirmed their proposal. In fact, in the BE06 corpus, we have found infinitive phrases as complements of directive verbs and evaluative predicates (26), modal verbs (27), desiderative verbs (28), thinking verbs (29), communicative verbs (30), and cognition verbs (31). In all these contexts, we have noticed the use of the full infinitive.

(26) It's not necessarily a bad thing if they've come to this area recently, as long as you are happy with their creativity and general expertise. Ask to see complete wedding albums - it's important to see the full scope of their work, not just the best bits.

(27) The MCB believes, that we have therefore to do more than just remember and reflect on the past - we must be able to see when the same abuses occur in our own time.

(28) Sir Alex Ferguson knows, from the defeat inflicted on a young Manchester United side which played Fenerbahce three years ago, that fielding an under-strength team after European qualification is assured can be risky. "We don't want to send teams out there to get humiliated or embarrassed, that's for sure," he said yesterday, recalling that occasion, when a Tuncay Sanli hat trick did for United, 3-0.

How dare you suggest such a thing?

"Do not think to play me for a fool, Cousin," Max replied.

(30) But despite no one having seen him, except maybe for a trail of stardust in his wake, or the sound of a jingle bell in the distance many claim to know who he is.

(31) She wrote it down in yellow chalk: BESSI BEST BED, on the wall where her eyes landed in the mornings, just by the attic cupboard where things could be hidden, whole people could be hidden and no one would know to look there because you couldn't stand up in it and it was full of old books and buckets and spades for the holidays.

\subsection{Infinitive phrases preceded by auxiliary verbs: verbal periphrases}

In Mayerthaler et al. (2001) model, infinitives of a considerable number of European languages are preceded by auxiliary verbs. An auxiliary verb is defined by Diller (1988) as a verb that has a functional task in the sentence, i.e., to offer further syntactic or semantic information of the main verb in a sentence or a clause. The syntactic information it offers is related to mood and modality, voice, aspect and tense. In other words, an auxiliary verb, known also as a "helper verb", helps or modifies the main verb and its use in the sentence can accurate the meaning of the message.

If we want to come up with a list of what we have considered an auxiliary verb for this study, then it must be stated that we have considered the following verbs: can, could, may, might, must, shall, should, will, would, do, did, ought, need, dare and have. We have not considered be as an auxiliary verb because it does not modify another verb. Besides, in the context in which we have found the verb be is more of a copula or a linking verb, as we will see later.

In the BE06 Corpus, the most frequent context in which infinitives are used is precisely with auxiliary verbs. In most of these contexts, we have found the bare infinitive. In fact, in our search of auxiliary verbs + bare infinitive in the CQPweb, the system displayed 5,005 matches in 496 different texts. This means that there were only 4 texts without these verbal periphrases. Certainly, we have observed the bare infinitive after auxiliary verbs such as: will (32), would (33), can (34), could (35), and others.

(32) Chairman of the Conservative Ethnic Diversity Council Lord Sheikh said: MINAB will take a very positive step providing practical advice, guidance and support which will enable the stakeholders to achieve self-regulation. It will also help to improve the quality of the work they undertake and the provision of various services.

(33) Richard: Tell me, if a friend wanted to go on Big Brother what would you say?

Gerry: I'd say, Are you serious?

(34) But we can't continue to blame the Tories for the lack of housing when we've had over a decade to sort it out.

(35) The very act of using the concept brings it alive. We could not research processes of inclusion/exclusion without being a part of their construction. 
With the auxiliary ought, as we can see in example (36), the infinitive phrase is introduced by the particle to. With the auxiliary have, it is obligatory to use the full infinitive too, as we distinguish in (37). In the BE06 Corpus, we have found 496 examples of these two periphrases in 250 different texts.

(36) We pay, you and I and everybody else actually pays direct or indirect taxes and it's there for everybody's benefit not one or two... if you are entitled to it you really ought to accept that money... there's no charity in any shape or form.

(37) “I don't know, but Cedric Owen did it for hundred and nineteen years ago without magnesium flares or a neoprene drysuit and he came out alive, so we have to assume that it's not as terrifying as it looks.

Finally, we consider it important to state that in his contrastive study between French and English infinitives, Turner (2001: 105) asserts that verbs such as dare and need have the particularity of being followed by the bare infinitive or the full infinitive, as we can see in examples (38-43). Nevertheless, it is important to mention that we never found an example with $d o /$ did + dare + full infinitive in the BE06 Corpus, such as in the example (41) which is provided by Turner (2000). Besides, in the corpus, we encountered 236 examples with need + full infinitive, 10 examples with dare + full infinitive, 7 examples with dare + bare infinitive, and only one example with need + bare infinitive.

(38) We have more in common with France than we dare admit, but at least it is trying to treat the problem.

(39) He had bravely come to terms with the fact that he would never dare to speak, and there was no need for him to dare to speak, and he had begun to enjoy sitting there anonymously in the pavilion with its faint unthreatening aroma of the stale sweat of generations of jockstraps.

(40) You should also prepare yourself for three years of social disappointment, eventual marriage to a terribly dull man called Malcolm, and no real experience of orgasm until you flee the marital home in your mid thirties and take solace in the delights of the love that dare not speak its name with a strong-wristed lady from Munich named Gerta.

He didn't dare to stay any longer. (Turner, 2000: 105)

(42) Just as we can now see clearly the inadequacy of St Paul's teaching on women or slavery, and excuse his historical limitations, so we need not blame him for his lack of understanding of the concept of same-sex love.

(43) The fact that you do not need to ask for details of them is proof enough for me, Cousin.

\subsection{Infinitive phrases as verb subjects and nominal predicates}

Besides the function of verb complement and verbal periphrasis, infinitives can figure as verb subjects of the sentence in a large number of languages. Nevertheless, Gawelko (2005:141) asserts that the infinitive phrase as a verb subject is not so frequently used in Romance languages and English. In fact, in Quintero Ramírez (2012) we observe this peculiarity in Spanish and French where the function of verb subject in the infinitive of both languages is not as recurrent as other syntactic functions such as the verbal periphrases or the verb complements registered in the study about a contrastive analysis of syntactic functions of infinitives in these two languages.

If we consider English, it must be noticed that infinitives in this specific syntactic function are full infinitives. According to Gawelko (2005), in English it is not very common to find infinitive phrases displaying this syntactic function because it is more common to find a gerund. In fact, in the BE06 Corpus, we have encountered 23 examples with the -ing form; whereas we have barely found 4 examples of infinitive phrases as verb subjects. From these 4 examples, 2 were subjects of the verb be and another infinitive phrase that was considered a nominal predicate, as we can distinguish in (44). And the other 2 infinitive phrases were subjects of lexical verbs; we can see an example in (45). The difference between the infinitive and the -ing form in this particular syntactic function is not very clear. We agree with Duffley (2003: 350), who states that "the distinction in meaning between these two constructions is more complex than that of a simple binary opposition." Furthermore, the author says that both forms can occur as subjects of the same predicates.

(44) To act virtuously is to act from inclination formed by the cultivation of the virtues.

(45) To answer this question requires commentary on MacIntyre's notion of virtue and its relationship to goods, practices and institutions.

Besides the 4 examples of infinitive phrases as verb subjects, in the BE06 Corpus we have encountered 2 infinitive phrases whose syntactic function is a nominal predicate. The only reason we have considered these 2 infinitive phrases as nominal predicates and not as verb subjects is because they occupy the subsequent position to the verb be. We have examined one example in (44) and we can observe the other example in (46).

(46) She has told me artlessly that her ambition is to perform circus tricks like Madame Scacchi, \& that she is acting the courtesan to pay the lessons in circus craft.

It is important to mention that we have found other 7 examples with a bare infinitive after the verb be conjugated in third person singular present indicative. The construction in all the examples has been: all + personal pronoun + verb (have to/ want to/ need to/ can) + do + is + bare infinitive. An example is seen in (47).

Science has the answer. All you have to do is clone the perfect blonde.

Nevertheless, in the corpus we have found a very similar construction with the verb propose, and the bare infinitive phrase changes to a full infinitive phrase, as can be distinguished in (48). 
(48) What I propose to do is to examine the main fragments of that rubble, Panofsky's essay and structuralist psychoanalytic theory, in order to discover what assumptions and implications are latent in the new paradigm.

\subsection{Infinitive phrases as noun complements and adjective complements}

Another two syntactic functions of infinitive phrases are those of noun complement and adjective complement. Gawelko (2005: 142) reveals that these functions of the infinitive are common in Germanic and Romance languages. An example of an infinitive phrase as a noun complement and another example of infinitive phrase as an adjective complement can be encountered in (49) and (50) respectively. In the BE06 Corpus, we have found 2,196 examples of infinitive phrases displaying the function of noun complement. We have also discovered 1,110 examples of infinitive phrases performing the syntactic role of adjective complement. This leads us to conclude that although these two syntactic functions are not as common as those of verbal periphrases or verb complements, they are both very common in British English. In all the examples found, the full infinitive was used, since the particle to can be considered a nexus between the noun or the adjective and the infinitive.

(49) Flight could be justified, and was the preferred choice for most of those, the rich and powerful, with the ability to leave.

(50) Then, without a glance at Perowne, they set off back up the road. Hard to imagine they don't think something is wrong with Baxter.

\section{Conclusions}

After the analysis of the BE06 Corpus, it can be concluded that English infinitive is a non-finite form that has verbal and nominal characteristics. These traits are not dichotomist but complementary. Indeed, infinitives in English have the possibility of taking verb complements in order to constitute an infinitive phrase [to read a book]. As infinitive phrases, they can fulfil several syntactic functions that are usually fulfilled by nominal phrases. In fact, in the corpus we have noticed that infinitive phrases are used as verb complements, verbal periphrases, verb subjects, nominal predicates, noun complements and adjective complements.

Besides the verbal and nominal traits of English infinitives, we have identified some relevant contexts in which the English infinitive is used as a full infinitive and those contexts in which it is used as a bare infinitive. On the one hand, the contexts in which English infinitive must not be preceded by the particle to are: a) after the auxiliary verbs such as will, would, can, could, shall, should, and others; b) after perception verbs such as see, watch, hear, feel, etc.; c) after permission and causal verbs such as let and make; and d) after the verb be as a nominal predicate in constructions such as: all you have to do is clone the perfect blonde.

On the other hand, the contexts in which English infinitive is preceded by the particle to are: a) as a verb subject: To act virtuously is to act from inclination formed by the cultivation of the virtues; $b$ ) after a considerable number of direct objects in many transitive verbs: conversations that would force him to say unkind things; c) after the verb be as a nominal predicate: her ambition is to perform circus tricks; d) as noun and adjective complements: ability to leave/ hard to imagine; and e) after the auxiliary verbs ought and have: you really ought to accept that money/ we have to assume that it's not as terrifying as it looks.

Furthermore, we have seen in the corpus that verbs such as help and dare take full infinitives and bare infinitives as well. With help we have found examples such as: the syllabus can help students to understand a "troublesome concept"/ our commitment to help communities tackle bad landlords. With the verb dare we have found examples such as: We have more in common with France than we dare admit/ He had bravely come to terms with the fact that he would never dare to speak.

Finally, we must admit that this study presents only a general overview of the syntactic functions the English infinitive can take within the sentence, based on the BE06 Corpus. Consequently, further research must be done in order to determine other functions this non-finite form can fulfil not only at the level of the sentence, but also at a suprasentential level, such as a linking technique in adverbial complements or as an independent construction.

\section{References}

Barron, J. (2000). The morphosyntactic correlates of finiteness. Proceedings of the LFG00 Conference. http://web.stanford.edu/group/cslipublications/cslipublications/LFG/5/lfg00barron.pdf

Baker, P. (2009). The BE06 Corpus of British English and recent language change. International Journal of Corpus Linguistics, 14(3), 312-337.

Buridant, C. (1990). L'infinitif dans les langues romanes et las langues germaniques: essai d'approche typologique. In: Bechert, Bernini \& Buridant (eds.) Toward a typology of European languages (Empirical approaches to Language Typology), 8, 141-163.

Diller, A. V. N. (1988). Thai Syntax and "National Grammar". Language Sciences, 10(1), 273-312.

Duffley, P. (2003). The Gerund and the to-Infinitive as Subject. Journal of English Linguistics, 31(4), 324-352.

Gawelko, M. (2005). Quelques particularités de l'infinitif en espagnol et en portugais. Estudios hispánicos, 13(1), 167176. 
Hardie, A. (2012). CQPweb - combining power, flexibility and usability in a corpus analysis tool. International Journal of Corpus Linguistics, 17(3), 380-409.

Haspelmath, M. (1989). From Purposive to infinitive - A universal path of grammaticization. Lingüistica Histórica, 10(1), 287-310.

Hernanz Carbó, M. L. (1982). El infinitivo en español. Barcelona: Bellaterra.

Iturrioz Leza, J. L. (2000). Diversas aproximaciones a la nominalización. De las abstracciones a las macrooperaciones textuales. Función, 21-24(1), 31-140.

Mayerthaler, W., Fliedl, G. \& Winkler. C. (2001). Infinitivprominenz in Europäischen Sprachen. Tübingen: Projektbericht.

McEnery, A. \& Xiao, Z. (2005). HELP or HELP to: what do corpora have to say? English Studies, 86(2), 161-187.

Quintero Ramírez, S. (2012). Análisis contrastivo del infinitivo en español y en francés desde una perspectiva morfosintáctica. Lengua y Habla, 16(1), 150-171.

Raible, W. (2001). Linking Clauses. In Haspelmath König, Oesterreicher \& Raible (eds.) Language Typology and Language Universals - Sprachtypologie und sprachliche Universalien - La Typologie des langues et les universaux linguistiques. An International Handbook - Ein internationales Handbuch - Manuel international, 590-617.

Rémi-Giraud, S. (1988). L'infinitif. Lyon: Presses Universitaires de Lyon.

Sasse, H. J. (2001). Scales between nouniness and verbiness. In Haspelmath König, Oesterreicher \& Raible (eds.) Language Typology and Language Universals - Sprachtypologie und sprachliche Universalien - La Typologie des langues et les universaux linguistiques. An International Handbook - Ein internationales Handbuch - Manuel international, 495-509.

Schybsbye, K. (1965). A Modern English Grammar. Oxford: Oxford University Press.

Tesnière, L. (1976). Elementos de la sintaxis estructural. Madrid: Gredos.

Turner, N. (2000). Linguistique contrastive et traduction, étude contrastive de l'infinitif en français et en anglais. Paris: Ophrys.

Ylikoski, J. (2003). Defining non-finites: action nominals, converbs and infinitives. SKY Journal of Linguistics 16(1), 185-237.

\section{Notes}

Note 1. Sasse (2001) proposes the same continuum constituted by the concepts of nouniness and verbiness as the cornerstones.

Note 2. English infinitive does not let this happen: *This to think about you. Gawelko (2005) states that nominalization of infinitive does not exist in Rumanian, English or Polish.

Note 3. "The IMS Open Corpus Workbench (CWB) is a collection of open-source tools for managing and querying large text corpora (ranging from 10 million to 2 billion words) with linguistic annotations. Its central component is the flexible and efficient query processor CQP." (Hardie, 2012)

Note 4. CLAWS is a system of grammatical tagging to annotate a corpus. CLAWS achieves $96-97 \%$ accuracy. 